\title{
Slow tourism, una oportunitat per a la transformació del turisme?
}

Slow tourism, an opportunity for tourism transformation?

Izcara Conde, Carla a

Cañada Mullor, Ernest ${ }^{b}$

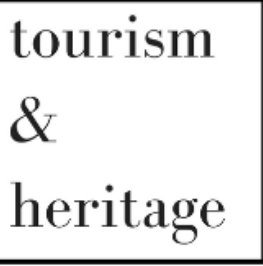

a Investigadora d'Alba Sud - centre independent d'investigació.

J O U R A L

Barcelona, Espanya. carla@albasud.org

b Coordinador d'Alba Sud - centre independent d'investigació i docent

del CETT-UB, Barcelona, Espanya. ernest@albasud.org

ARTICLE INFO

Historial de l'article:

Rebut: 24 agost 2020

Acceptat: 30 octubre

2020

Publicat: 31 octubre 2020

Paraules clau: enoturisme; gastronomia; postfordisme slow tourism; turismes de proximitat

\section{RESUM}

Aquest article, de caràcter assagístic, es proposa aclarir alguns dels conceptes amb els quals s'expressa el moviment slow en l'àmbit del turisme, així com introduir alguns dels debats que ha generat: les potencialitats de la seva associació amb un procés de revalorització de la gastronomia local, les motivacions del turista slow i, finalment, les oportunitats, però també contradiccions i limitacions d'una proposta d'aquest tipus per transformar el turisme en un sentit emancipatori.

\section{ARTICLE INFO}

\section{Article history:}

Received: 24 August 2020

Accepted: 30 October 2020

Published: 31 October 2020

Keywords:

Gastronomy; postfordism; proximity tourism; slow tourism; wine tourism

\section{ABSTRACT}

This essay-style article, aims to clarify some of the concepts with which the slow movement is expressed in the field of tourism, as well as to introduce some of the debates it has generated: the potentialities of its association with a process of revaluation of local gastronomy, the motivations of the slow tourist and, finally, the opportunities, but also contradictions and limitations of a proposal of this type to transform tourism in an emancipatory sense. 


\section{INTRODUCCIÓ}

L'slow tourism té el seu origen a principis de la dècada dels 2000 com una branca del moviment slow. La necessitat de desacceleració, davant les dinàmiques de producció i consum capitalista, cristal·litza com a forma d'acció social l'any 1986 a Itàlia, impulsada per Carlo Petrini, quan es confronta davant l'increment del fast food, que simbolitzava un creixement massiu i agressiu (hard growth), l'estrès i la falta de poder sobre les nostres vides (Timms i Conway, 2012).

El moviment slow pretenia canviar la forma de consumir béns i serveis (Calzati i De Salvo, 2018), deixant de banda el model de vida de la societat occidental, caracteritzat per la rapidesa i la insostenibilitat (Timms i Conway, 2012), i apostava per un consum i producció més sostenibles, de base local i amb consciència mediambiental (Chung et al., 2018). Aquesta filosofia es caracteritza, segons Calzati i De Salvo (2018), per tres elements principals: més temps, menys estrès i un major equilibri en el nostre dia a dia.

Els principis del moviment slow s'han relacionat amb la teoria del decreixement (De Luis, 2011), o com a mínim s'hi han identificat espais de proximitat. El decreixement posa en qüestió la lògica del creixement il-limitat i assenyala la necessitat d'impulsar un procés de transformació política i social que redueixi l'ús de materials, energia, recursos tecnològics i treball, alhora que millora la qualitat de vida de la població i fa un ús més eficient dels territoris (Latouche, 2006, 2007). El decreixement ha tingut múltiples interpretacions i influències d'altres corrents de pensament (Andriotis, 2018). No obstant això, hi ha prou consens per entendre que fonamentalment implica descolonitzar imaginaris àmpliament assentats en el paradigma del creixement (Demaria et al., 2019) i transitar de manera voluntària cap a un altre model d'organització social. Des d'aquesta perspectiva s'advoca per processos de transformació desitjats davant el risc que les crisis cícliques del capitalisme imposin altres formes de decreixement forçat (Blanco-Romero, 2019).

Aquesta perspectiva, que aposta per la necessitat d'una transformació del turisme amb la que connecta l'slow tourism, ha anat adquirint visibilitat renovada davant l'emergència de la crisi climàtica i, especialment durant l'any 2020, a causa de la pandèmia de la COVID-19. L'emergència climàtica requereix reduir la contaminació atmosfèrica, de la qual el transport a llarga distància i a gran escala n'és un dels principals responsables (Rico et al., 2019). L'aposta pels turismes de proximitat, i en concret per l'slow tourism, contribueix a relocalitzar l'activitat turística, promoure mitjans de transport més sostenibles i rebaixar la pressió climàtica. D’altra banda, els turismes de proximitat poden actuar com a dinamitzadors de l'activitat socioeconòmica a molts territoris que tradicionalment han tingut baixa intensitat turística. En un context determinat per la pandèmia de la COVID-19, que ha reduit extremadament les possibilitats de mobilitat internacional, la dinamització del turisme domèstic adquireix un clar protagonisme (Cañada, 2020).

En aquest marc, el present article, de caràcter assagístic, es proposa aclarir alguns dels conceptes amb els quals s'expressa el moviment slow, i en particular l'slow tourism, així com introduir alguns dels debats que ha generat: les potencialitats de la seva associació amb un procés de revalorització de la gastronomia local, les motivacions del turista slow i, finalment, 
les contradiccions i limitacions d'una proposta d'aquest tipus per transformar el turisme en un sentit emancipatori.

\section{DIMENSIONS DEL MOVIMENT SLOW}

Dins del moviment slow, apareixen iniciatives com l'slow food, les slow cities o l'slow tourism que assenyalen camins que ens podrien ajudar a avançar cap a una transformació del sistema actual de producció i consum en el marc d'una transformació socioecològica cada vegada més urgent i socialment demandada.

\subsection{Slow food}

L'slow food, reivindica la cultura gastronòmica local, contraposa una visió ètica de la producció i el consum (Valls et al., 2019). Es va entendre com una proposta de creixement organitzat, pausat i sostenible (soft growth) (Timms i Conway, 2012), davant formes superficials o banals de consum en forma de menjar ràpid o de visites programades fetes a correcuita.

Carlo Petrini explica els principis de l'slow food com a moviment iniciat als anys 80 a Itàlia al llibre Slow Food: The Case for Taste (2003). En primer lloc, es considera l'alimentació com una part essencial de la vida i la qualitat d'aquesta estaria lligada al plaer d'ingerir aliments saludables i de temporada. Així, es valoren els diferents sabors i formes de consum d'aquests aliments, sempre reconeixent el treball de tota la cadena de producció. D'altra banda, aquest moviment no només busca gaudir dels aliments sinó que ajuda a un desenvolupament més sostenible de les explotacions agràries recuperant també tècniques de conreu tradicionals i promovent el consum de productes locals. Així mateix, la globalització alimentària ha fet que augmenti la preocupació per reivindicar el valor nutricional, cultural, social i simbòlic dels aliments (Hernández et al., 2020).

\subsection{Slow cities}

Un cop iniciat el moviment de l'slow food, es va anar reproduint en altres àmbits com ara la manera de concebre les ciutats i el seu funcionament. A finals dels anys 90, a Itàlia, es va iniciar el moviment de les ciutats slow i es va fundar l'associació "Cittaslow, Rete Internazionale delle città del buon vivere" que després s'aniria estenent arreu del món. Aquestes xarxes de municipis aposten per un desenvolupament sostenible basat en la gestió local del territori amb l'objectiu de mantenir la qualitat de vida i el benestar col-lectiu (Presenza et al., 2014; Donaldson, 2017). Tant les slow cities com l'slow food aposten per la producció i gestió local, promouen un ritme de vida relaxat i conserven les tradicions culturals (Donaldson, 2017).

Per obtenir el certificat de "Cittaslow" s'han de complir una sèrie de requisits com, per exemple, no sobrepassar els cinc mil habitants o donar suport a l'agricultura, la gastronomia i el comerç local (De Luis, 2011). Aquest certificat ajuda a conservar el paisatge i el patrimoni cultural local a l'hora que contribueix a la promoció del territori, esdevenint un clam pels turistes amb interessos culturals (De Luis, 2011; Presenza et al., 2014). Aquest certificat també impulsa formes alternatives de turisme, allunyades del turisme massiu i del 
consum accelerat de béns i serveis assegurant l'autenticitat de les experiències i la conservació del patrimoni cultural (Presenza et al., 2014).

\subsection{Slow tourism}

L'slow tourism, com tot concepte que intenta posar nom a una pràctica social plural, ha estat sotmès a nombroses discussions i ha evolucionat al llarg del temps. Actualment es considera que no existeix una definició compartida amb suficient consens (Serdane et al., 2020). En un primer moment, es va entendre com una pràctica turística més respectuosa amb el medi ambient i s'incidia en la importància d'utilitzar mitjans de transport menys contaminants com ara la bicicleta o fer rutes a peu, ressaltant la rellevància del trajecte i el que pot aportar a l'experiència del viatge en conjunt (Wilson i Hannam, 2017). Donava forma així a un compromís ecològic que articulava un turisme relocalitzat en la proximitat.

Posteriorment, van anar prenent força tres elements claus que caracteritzen aquest moviment: la reducció de la petjada de carboni, l'augment del benestar i la connexió amb el territori. Així es detecta una interpretació generalitzada que descriu l'slow tourism com una actitud al viatjar i que considera que no es pot classificar com una tipologia de turisme o una classe de turista (Oh et al., 2014; Özemir i Çelebi, 2018; Serdane et al., 2020). S'introdueix també la idea de la necessitat de valorar més la qualitat en lloc de la quantitat, oposant-se d'aquesta manera al fet que el desenvolupament d'una destinació es mesuri únicament per l'arribada de turistes (Timms i Conway, 2012), la qual cosa trenca amb el que s'ha considerat fins ara "èxit turístic". Per tant, a priori, l'slow tourism intentaria evitar els impactes negatius del turisme de masses (Timms i Conway, 2012; Donaldson, 2017; Özemir i Çelebi, 2018) i s'articularia com una proposta ètica en el context de les pràctiques turístiques (Calzati i De Salvo, 2018; Valls et al., 2019; Serdane et al., 2020). Aquesta nova manera de viatjar s'alça també de manera privilegiada com una oportunitat per connectar amb la natura i els paisatges rurals (Varley i Sample, 2015) i per revalorar el patrimoni cultural construït sobre aquests territoris (Moscarelli, 2019). L'slow tourism pot contribuir a valorar elements patrimonials fora dels circuits turístics massius contribuint així a la conservació i a la redistribució dels fluxos turístics. Així mateix, en la mesura que aquesta ha estat una pràctica característica de les àrees rurals es proposa com a eina per revitalitzar espais rurals afectats per l'èxode i l'abandonament (Moscarelli, 2019). Un exemple són les "Vies verdes", antics trams ferroviaris en desús que s'han condicionat per fer senderisme o bicicleta. Aquest projecte, vinculat també al turisme industrial, ha ajudat a recuperar el patrimoni ferroviari a Espanya revitalitzant zones rurals deprimides a l'hora que promou una mobilitat sostenible i es postula com una alternativa turística per connectar amb el paisatge i conèixer la història d'un territori (Abellan, 2020).

\section{GASTRONOMIES LOCALS I SLOW TOURISM}

Una de les característiques principals de l'slow tourism és poder disposar de més temps en viatjar i el desig per connectar amb el territori visitat. Davant d'aquest nou escenari, propostes com les del turisme gastronòmic, apareixen com una bona opció per desaccelerar i apropar-se a la cultura local. L'interès per la gastronomia local ha esdevingut un terreny fecund per la relació entre el turisme gastronòmic i l'slow tourism. 
L'alimentació pot ser un bon recurs per conèixer la cultura d'un país i ja s'ha transformat en un símbol d'identitat (Hernández et al., 2020; Hernández i Dancausa, 2018). Existeix una relació molt estreta entre la dieta d'una zona, el seu paisatge i les capacitats de producció locals. Esdevé una "expressió directa d'interacció entre la natura i la cultura en un entorn específic" (Corvo i Matacena, 2017: 99). La cultura alimentària d'un lloc és el conjunt de pràctiques, coneixements, tècniques i creences que fan referència a tot el que envolta l'alimentació; des de formes de producció i elaboració fins a costums i formes de consum, totes elles susceptibles de patrimonialització (Espeitx, 2004).

El procés de patrimonialització és una redefinició o reelaboració del patrimoni col·lectiu real, pel qual se seleccionen uns elements sobre uns altres. Aquesta tria està relacionada amb la imatge que es vol projectar d'un territori i les estratègies que es volen desenvolupar en matèria turística (Ellison, 2017). En conseqüència, els elements que es converteixin en patrimoni no representaran completament la cultura alimentaria d'una zona (Espeitx, 2004). Destaquen tres manifestacions de protecció de productes agroalimentaris i gastronomies que han permès la consolidació d'un patrimoni alimentari: l'aparició i extensió de les denominacions d'origen protegides, l'augment d'investigacions i inventaris de productes alimentaris a una determinada zona i, finalment, la convenció de la UNESCO de 2003 que va afavorir la consideració de l'alimentació com a patrimoni de la humanitat (Ribas i Mulet, 2018). La UNESCO marca que les pràctiques culturals han de ser vives i integrar transformacions però així i tot, hi ha actors que tendeixen a immobilitzar practiques alimentàries en gran part desaparegudes (Suremain, 2017). Aquest procés no està exempt de riscos i contradiccions. Ribas i Mulet (2018) assenyalen la paradoxa que suposa l'intent de protegir l'especificitat de la cultura alimentària local davant els processos d'homogeneïtzació global i, al mateix temps homogeneïtzar i convertir en estereotips productes alimentaris, cuines i gastronomies en certs territoris.

Tots aquests elements i en concret la producció d'aliments i les cuines i gastronomies locals, poden convertir-se en recursos turístics en si mateixos i esdevenir una motivació per viatjar. Al mateix temps, en un context de fragmentació, segmentació i particularització dels mercats turístics, guiats sota una lògica postfordista de reorganització de la producció i consum capitalista (Ioannides i Debbage, 1998), i que es tradueix també en una nova territorialitat (Rullán, 2008), l'oferta vinculada al patrimoni alimentari sembla tenir una especial potencialitat. Així, monuments, festivitats, tradicions i aliments, esdevenen possibles objectes de consum i poden banalitzar-se i desvincular-se dels seus significats i valors. Les dinàmiques de patrimonialització poden respondre tant a una voluntat de recuperar o conservar elements d'identitat d'una cultura, com a una lògica de patrimonialitzar tot allò que pugui ser comercialitzable.

De fet, el patrimoni alimentari es pot modificar constantment per adaptar-se a les preferències del visitant $o$ a noves circumstàncies, mantenint alguns elements que el fan identificable (Espeitx, 2004). Així, a partir de l'anàlisi de les experiències vinculades al projecte europeu MEDFEST Culinary heritage experiences: how to create sustainable tourist destinations s'identifiquen dinàmiques de mercantilització i d'espectacularització, associada a la creació de certes ficcions de la vida social vinculada a la producció alimentària per tal de facilitar el seu consum (Ribas i Mulet, 2018). Per evitar aquestes conseqüències 
s'ha d'incloure la població local en el procés de presa de decisions sobre què i com incloure certs elements culturals a l’oferta turística (Zúñiga, 2012).

No sense riscos de caure en aquest tipus de dinàmiques, certes formes d'organitzar l'activitat turística, com per exemple el turisme gastronòmic quan es vincula a la filosofia de l'slow tourism, poden ajudar a donar a conèixer la producció alimentària i la seva gastronomia a determinats territoris. En aquest procés també hi pot haver un apropament a la població local. Així l'slow tourism potenciaria pràctiques turístiques que valoren el temps de preparació dels aliments, verifiquen la qualitat i sostenibilitat dels productes o ressalten la importància d'interactuar en compartir un àpat (Corvo i Matacena, 2017). Per tant, en vincular-se a una proposta d'slow tourism, el turisme gastronòmic pot contribuir a estimular l'agricultura local a l'hora que ajuda a conservar i revalorar la cultura d'aquell indret, i en particular a estimular la producció alimentària lligada a unitats familiars camperoles (Gascón, 2018). En conseqüència, es desenvolupa un sentiment d'apropiació territorial i cultural preservant així la identitat d'un territori en un context de globalització i homogeneïtzació (Corvo i Matacena, 2017), un procés que no és aliè tampoc a riscos i contradiccions.

Aquesta relació entre turisme, producció alimentària i gastronomia, que permet una reorganització de les pràctiques turístiques a partir del moviment slow ha estat identificada en diferents contextos. Així s'han destacat experiències com les del turisme vinculat al coneixement i consum de productes alimentaris com el cafè en contextos tan diferents com Costa Rica (Candelo, 2019), El Salvador (Cañada, 2017), Indonèsia o Etiòpia (Woyesa, 2020), en els quals s'identifiquen evidències positives en termes de diversificació i complementarietat d'ingressos, obertura de nous mercats per a la comercialització de la producció de cafè i la conservació dels recursos naturals. Però probablement l'enoturisme, i en particular l'experiència desenvolupada a Catalunya, pugui servir com a exemple virtuós de les potencialitats d'un turisme slow que centra la seva atenció en la cultura del vi i el cava.

\subsection{Enoturisme a Catalunya}

Aquesta última dècada hi ha hagut un creixement del turisme gastronòmic i l'entourisme a Espanya i s'ha acabat consolidant com un producte independent. A Catalunya, territori amb llarga tradició agrària, s'ha apostat per aquesta iniciativa turística per tal de diversificar l'oferta i ajudar al desenvolupament econòmic de les zones rurals a la vegada que s'ha recuperat i revalorar el treball i els coneixements del camp (Molleví i Fusté, 2016). Aquestes propostes turístiques s'organitzen en formes de rutes gastronòmiques les quals inclouen vistes als atractius culturals i naturals de la zona amb la possibilitat de complementar-ho amb altres serveis turístics com ara una oferta d'allotjament o esports d'aventura. D'altra banda, fomenten la col-laboració entre els agents públics i privats, ja que aquesta estructura implica diferents actors (Jeambey, 2016).

Pel que fa a les rutes gastronòmiques on es destaca un producte en concret, les rutes del vi i el cava són les més conegudes i assentades al marc europeu amb especial èmfasi a Espanya i Catalunya (Jeambey, 2016). En el cas del vi a Catalunya, la comunitat compta amb dotze Denominacions d'Origen Protegides i totes elles estan relacionades amb diferents rutes gastronòmiques. Aquest segell per una banda estableix uns estàndards de qualitat i 
assegura la presència d'una varietat de raïm concret $i$, per una altra, garanteix unes formes de cultiu i elaboració característiques del territori i relacionades amb la tradició i cultura locals oferint un valor afegit a l'hora de realitzar la promoció turística (Medina i Tresserras, 2008; Jeambey, 2016; Molleví i Fusté, 2016).

La segona ruta del vi i el cava més important en l'àmbit estatal es troba a Catalunya a la zona del Penedès amb 441.467 visites anuals (ACEVIN, 2019), on participen tres bodegues internacionals de renom, les Caves Codorniu, Freixenet i les Bodegues Torres, a més d'altres de diferents dimensions. El conjunt d'activitats enoturístiques que s'organitzen sota el nom d'EnoturismePENEDÈS inclouen des de visites a les vinyes i bodegues o tasts de vins fins a la visita al Museu de les Cultures del Vi de Catalunya, el VINSEUM, fundat l'any 1945 a Vilafranca del Penedès, el primer museu de la temàtica a escala estatal. Les característiques principals que han fet que aquesta ruta sigui de les més exitoses són la forta presència de les marques esmentades als mercats internacionals i que s'hi pot arribar en tren des de Barcelona, focus turístic molt important (Molleví i Fusté, 2016). Dins de les diferents opcions que ofereix, volem destacar la ruta "Slow bike". Aquesta ruta es caracteritza per tenir una durada de quatre dies, fet que permet al turista visitar les bodegues, gaudir del paisatge i dels atractius culturals i connectar amb la població local sense la pressió del rellotge. Cal destacar que aquesta oferta dins del marc de l'slow tourism compleix amb diversos requisits com és ara l'abundància de temps i el respecte pel medi ambient. Així i tot, l'oferta se centra en tres grans empreses dificultant la participació de petites i mitjanes bodegues (Medina i Tresserras, 2008). També cal apuntar que a vegades, l'etiqueta slow s'utilitza com un clam comercial o eina de màrqueting i no per establir uns principis més sostenibles dins de l'activitat turística.

Tot i això, a la zona també han sorgit altres propostes arrelades al territori protagonitzades per petites empreses o vinculades a l'Economia Social i Solidària. Així, per exemple, a la mateixa zona del Penedès es troba l'empresa "Cava Emotions"; una petita agència receptiva ubicada a Sant Sadurní d'Anoia que, tot i les dificultats per garantir la seva continuïtat empresarial, realitza visites a mida tant per particulars com per empreses. Dins de la seva àmplia oferta d'activitats es detecten diverses característiques que es podrien incloure dins d'una oferta turística slow. En primer lloc, s'utilitzen transports poc contaminants com ara les bicicletes o les rutes es realitzen directament a peu. En segon lloc, es visiten diferents cellers, tant de petits productors com d'altres coneguts internacionalment. Alhora, donen l'opció de conèixer tècniques de viticultura orgànica promovent així formes de producció més sostenibles. En quart lloc, tots els àpats s'elaboren amb productes locals i s'utilitzen receptes tradicionals. Finalment, destacar la finalitat educativa de totes les rutes, ja que el turista està en constant contacte amb els viticultors i també s'inclouen visites a alguns equipaments culturals de la zona com el Centre d'Interpretació del Cava o el Museu de la Xocolata de Simón Coll.

Trobem també propostes d'enoturisme dins de l'Economia Social i Solidària com per exemple la del Celler Comalats, ubicat a l'Ametlla de Segarra, Lleida. Aquest celler familiar ofereix visites a les vinyes complementades amb propostes gastronòmiques o culturals com ara representacions teatrals o concerts de petit format. En segon lloc, al Bages, es troba la primera Cooperativa productora de Cava de l'Estat espanyol amb més de cent anys d'història. La visita guiada al Celler Cooperatiu d'Artés inclou l'entrada al museu i a les caves, 
junt amb un tast de set vins i caves maridats amb productes de la gastronomia local. En últim lloc, igualment es pot destacar la proposta del Mas Vida, una petita bodega artesanal de l'Alt Empordà, que complementa les ofertes ecoturístiques i gastronòmiques amb propostes musicals. A més, organitzen excursions en Kayak pel Cap de Creus o el Fluvià acompanyat d'un tast de vins i olis posterior.

Aquestes experiències mostren la possibilitat que, sota el paraigua de l'slow tourism, es pugui produir dinàmiques que contribueixin a revalorar el patrimoni cultural i frenar l'èxode rural així com redistribuir els fluxos turístics i en conseqüència, els beneficis econòmics generats. Així i tot, trobem clares limitacions en aquesta estratègia, com pot ser la baixa participació de petites i mitjanes empreses o que els productes turístics comercialitzats acostumen a tenir tarifes altes, excloent gran part de la població.

\section{MOTIVACIONS DEL TURISTA SLOW}

La literatura científica ha descrit nombroses i diferents motivacions que han dut a algunes persones a apostar per l'slow tourism i, per tant, a intentar viatjar d'una forma més pausada i sostenible. En primer lloc, es destaca la voluntat del turista per reduir el seu impacte mediambiental (Timms i Conway, 2012; Donaldson, 2017; Barr, 2018; Calzati i De Salvo, 2018; Özemir i Çelebi, 2018). En el cas dels turistes amb motivacions culturals també es detecta una preocupació pel medi ambient (Garfield a Modéjar et al., 2009).

En segon lloc, hi ha una forta orientació cap a activitats de turisme vivencial (Meng i Choi, 2016). Així, s'argumenta, que els turistes que practiquen slow tourism poden conèixer el territori visitat tenint experiències que són considerades més autèntiques, genuïnes i significatives (Meng i Choi, 2016; Donaldson, 2017; Calzati i De Salvo, 2018; Shang et al., 2019). Pel que fa als turistes amb interessos culturals també rebutgen les realitats simulades o les falses representacions culturals (Smith a Mondéjar et al., 2009).

En tercer lloc, es valora que sota aquesta forma d'entendre el turisme, el consumidor deixa de ser un element passiu a la cadena i esdevé un "co-creador" del valor social que es genera a partir de l'experiència turística (Calzati i De Salvo, 2018). D'acord amb aquesta forma d'entendre la participació, s'origina una major interacció amb la població local (Özemir i Çelebi, 2018; Shang et al., 2019) i, en conseqüència, el turista experimenta un sentiment de pertinença o vinculació major cap al territori visitat (Shang et al., 2019; Valls et al., 2019). En el cas dels turistes amb interessos gastronòmics, els seus viatges també tenen una funció social molt important, acostumen a viatjar en grup i el moment de l'àpat és una oportunitat per compartir i socialitzar, tant amb els seus companys de viatge com amb la població local. No només busquen degustar plats sinó que valoren la possibilitat de conèixer hàbits de consum, rituals o receptes i a partir d'aquí la cultura de la localitat (Oliveira, 2011).

En quart lloc, diversos autors recalquen la cerca del benestar com una de les principals motivacions d'aquesta forma d'entendre el turisme. Tots ells coincideixen que disminuint el ritme del viatge els efectes positius en la salut, en un sentit ampli, són majors (Oh et al., 2014; Barr, 2018; Calzati i De Salvo, 2018). Així, el desig per desaccelerar i relaxar-se es consideren part també de les motivacions principals a l'hora de fer slow tourism (Oh et al., 2014; Özemir i Çelebi , 2018; Shang et al., 2019). De forma relacionada, també es detecta 
que algunes persones opten per l'slow tourism quan volen fer un viatge que els ajudi a fer una introspecció interna (Varley i Sample, 2015; Özemir i Çelebi, 2018). D'altra banda, s'ha identificat que els turistes que viatjaven sols es veien motivats també per l'interès en la novetat (Özemir i Çelebi, 2018).

Per últim, dins del marc de l'slow tourism es poden incloure diferents interessos turístics com ara els culturals o gastronòmics. Tots aquests turistes tenen dos punts en comú destacables. Per una banda tots viatgen motivats per conèixer la cultura local i viure una experiència considerada autèntica. Per l'altre, tots ells tenen un nivell d'estudis superior i un pressupost mitjà-alt (Mondéjar et al., 2009; Oliveira, 2011; Özemir i Çelebi, 2018; Shang et al., 2019).

\section{CONTRADICCIONS I LÍMITS DE LA PROPOSTA}

Malgrat les bones intencions que se li pressuposen, les pràctiques associades a l'slow tourism acumulen també contradiccions que han generat un fort debat sobre les seves implicacions. Hi ha autors que han emfatitzat algunes contradiccions entre la filosofia del moviment i algunes de les seves pràctiques. Originalment, l'slow tourism no estaria tan condicionat pel temps com altres pràctiques turístiques convencionals. Contràriament, s'intentaria evitar horaris estrictes i valorar el temps en funció de l'experiència del moment i de la possibilitat de gaudir-lo tranquil-lament. Així i tot algunes de les formes a través de les quals ha estat comercialitzat inclourien alguns elements que precisament es caracteritzarien per la seva rapidesa, com el transport aeri o Internet. Així s'ha qüestionat fins a quin punt és compatible una mentalitat slow amb pràctiques fast (Serdane et al., 2020).

Un altre element en debat destacat ha estat què quedaria de la contribució al medi ambient que pretenia afavorir inicialment l'slow tourism. D'aquesta manera, s'ha posat en dubte la coherència de l'ús de l'avió o altres mitjans de transport de llarga distància per arribar a determinades destinacions, encara que un cop allà se segueixin principis identificats amb l'slow tourism (Donaldson, 2017; Serdane et al., 2020). De fet, detectem diverses ofertes classificades dins de l'slow tourism dirigides sobretot al turisme internacional. A partir d'aquesta contradicció sorgeixen diverses qüestions com si es poden seguir considerant slow tourism pràctiques que impliquen desplaçaments a llarga distància per vies convencionals si un cop a la destinació s'adopten principis i pràctiques de la filosofia slow, tal com argumenten alguns autors (Meng i Choi, 2016). Quina seria aleshores la contribució d'aquesta forma de fer turisme en la reducció a l'empremta de carboni que inicialment es pretenia?

Per altra banda, la priorització de la proximitat també ha estat qüestionada des de diferents perspectives. Així, hi ha qui ha considerat que l'eliminació de mitjans de transport de llarga distància comportaria escollir destinacions més properes, accessibles en cotxe, autocaravana, bicicleta o fins i tot a peu. Aquesta orientació podria impactar negativament de dues maneres diferents: es considera que l'slow tourism esdevindria una alternativa limitada a les regions més benestants del planeta excloent les destinacions de difícil accés o més llunyanes (Donaldson, 2017) i, d'altra banda, el fet de viatjar de forma local suposaria una davallada en la demanda d'allotjament $i$, en conseqüència, un impacte en l'economia 
local (Serdane et al., 2020). Aquestes crítiques però menystenen la capacitat de dinamització econòmica local de les propostes de proximitat perquè probablement limiten la perspectiva a consums d'alt poder adquisitiu, el que posa en evidència la temptació elitista en la forma de concebre aquesta proposta.

Precisament, l'altre gran element en controvèrsia que s'ha produït al voltant de l'slow tourism ha estat el risc que quedés absorbit per dinàmiques de consum elitistes, dirigides a sectors de població amb major capacitat de consum que buscarien productes i experiències considerades de més qualitat i possibilitats de distinció. La incorporació d'elements i pràctiques que poden ser integrades en aquesta lògica de consum capitalista sota formes de distinció és realitzada constantment, encara que sigui assumint discursos contraculturals o suposadament alternatius (Frank, 2011). Així, hi ha qui alerta que la febre pel moviment slow pot jugar en contra de la seva mateixa filosofia original, convertint el que era una aposta per un consum més sostenible en un "producte mainstream" més. Autors com Meng i Choi (2017), Donaldson (2017) o Özemir i Çelebi (2018), esmenten que l'etiqueta slow és fonamentalment un clam comercial. Al llibre de Ronnie Donaldson, Small Town Tourism in South Africa (2017), s'il-lustren diferents casos on la comunitat percep el moviment slow com una imposició. Així es considera que les estructures organitzacionals d'aquestes "ciutats slow" no són gestionades des de la base i la presa de decisions recau en un grup reduït de persones de classe mitjana. En conseqüència, es crea una sensació d'elitisme i s'accentua la divisió d'opinions, ja que diferents membres de la comunitat pensen que es limita el desenvolupament d'altres activitats al territori. D'altra banda, la lògica d'una certa exclusivitat en l'oferta promoguda ha facilitat també el seu encariment (Varley i Sample, 2015) el que ha derivat en pràctiques turístiques que en alguns casos s'han considerat elitistes i excloents. De fet, diferents autors han detectat que la majoria de persones que practiquen l'slow tourism tenen estudis superiors o universitaris (Özemir i Çelebi, 2018; Shang et al., 2019), característica compartida amb els turistes amb inquietuds culturals o gastronòmiques. Inevitablement, aquestes crítiques obren l'interrogant de si ja en els seus orígens la proposta de l'slow tourism va estar marcada per aquesta voluntat de generar una oferta adreçada a sectors de major poder adquisitiu que fugien d'un consum més massificat. En qualsevol cas, la tensió per aquest elitisme ha estat sempre present.

Així mateix, la preferència de viatjar d'aquesta manera i viure experiències úniques pot acabar derivant en una sobrecàrrega de determinades destinacions que podria tenir efectes indesitjables, allunyant als mateixos turistes "slow" (Meng i Choi, 2016) i reproduint impactes semblants al turisme de masses en forma de friccions entre població local i turistes o falses autenticitats (Serdane et al., 2020).

\section{CONCLUSIONS}

L'slow tourism posa en qüestió un model de desenvolupament turístic que genera dinàmiques de despossessió i que banalitza l'experiència de conèixer i visitar territoris que no són els habituals. Contradiu també les bases de la producció i consum express de turisme de caràcter massificat. Dóna valor a altres formes de consum turístic i cultural que requereixen més temps i voluntat de connexió amb la realitat visitada. Les emergències globals que afronta la nostra societat, com la sanitària per COVID-19 i climàtica, limiten, 0 ho haurien de fer, el model de creixent constant de la mobilitat internacional a gran escala. 
En aquest context, hi ha un reconeixement cada cop més ampli de la necessitat d'una transformació del turisme i la importància de la proximitat. L'slow tourism, en la seva versió més preocupada pels impactes ambientals del turisme, pot ajudar a relocalitzar aquesta activitat i generar interrelacions que estimulin econòmicament i socialment determinats territoris.

No obstant això, probablement part dels seus límits tingui a veure amb el fet de ser propostes pensades més des de la demanda, sense tenir en compte les formes a través de les quals s'ha de garantir la seva producció. Al mateix temps, el seu desenvolupament pot derivar també en dinàmiques d'elitització del consum turístic que generin efectes d'exclusió. La seva història ens alerta sobre com pràctiques tradicionals poden ser reinterpretades a la llum de valors de distinció de sectors de major poder econòmic i acabar perdent potencialitat de transformació social de caràcter emancipatori, és a dir amb el propòsit moral d'eliminar qualsevol forma d'opressió o dominació i, al seu torn, afavorir una expansió de les capacitats humanes que permetin una vida digna en una societat justa en pau amb el planeta.

Tot i aquestes limitacions o contradiccions, l'slow tourism més que com a una resposta per ell mateix, més aviat s'hauria de considerar com a part d'un puzle complex de peces a articular entre elles per avançar cap a una transformació del turisme en un sentit més sostenible, equitatiu i inclusiu.

\section{AGRAÏMENTS}

Aquest article s'ha elaborat en el marc del projecte «Plataforma de recerca en turisme, drets humans i equitat de gènere sobre Amèrica Llatina» gestionat per Alba Sud amb el suport de l'Agència Catalana de Cooperació al Desenvolupament (ACCD) (convocatòria 2019).

\section{REFERÈNCIES}

Abellan, N. (2020). Turisme industrial, motor de canvi. Alba Sud, 14/08/2020. Recuperat de: http://www.albasud.org/noticia/ca/1244/turisme-industrial-motor-de-canvi

Andriotis, K. (2018). Degrowth in tourism. Conceptual, theoretical and philosophical issues. Wallingford: CABI.

Barr, S. (2018). Personal mobility and climate change. WIREs Clim Change, 9(5), 1-19.

Calzati, V. i De Salvo, P. (2018). Slow tourism. A theoretical framework. A M. Clancy (ed.), Slow Tourism, Food and Cities. Plance and the Search for the "Good Life" (33-49). New York: Routledge.

Blanco-Romero, A. (2019). Tourism degrowth. A E. Cañada (ed.). Tourism in the geopolitics of the Mediterranean (pp. 66-69). Barcelona: Alba Sud. Contrast Reports Serie, no. 9.

Candelo, E., Casalegno, C., Civera, C. i Büchi, G. (2019). A ticket to coffee: Stakeholder view and theoretical framework of coffee tourism benefits. Tourism Analysis, 24(3), 329-340.

Cañada, E. (2017). Contribución del turismo comunitario a la economía campesina: la Cooperativa Los Pinos en El Salvador. A J. Gascón i C. Milano (Eds.). El turismo en el mundo rural. ¿Ruina o consolidación de las sociedades campesinas indígenas? (pp. 111-137). PASOS, Colección PASOS Edita, 18.

Cañada, E. (2020). Turismes de proximitat, un plural en disputa. Alba Sud, 08/07/2020. Recuperat de: http://www.albasud.org/blog/ca/1236/turismes-de-proximitat-un-plural-en-disputa

Clancy, M. (2017). Slow tourism, food and cities. Pace and the search for the "good life". London: Routledge. 
Chung, J. Y., Kim, J. S., Lee, C. K. i Kim, M. J. (2018). Slow-food-seeking behaviour, authentic experience, and perceived slow value of a slow-life festival. Current Issues in Tourism, 21(2), 123-127.

Corvo, P. i Matacena, R. (2017). Slow Food in Slow Tourism. En Clancy, M. (ed), Slow Tourism, Food and Cities: Peace and Search for the "Good Life". London: Routledge Advances In Tourism.

De Luis, A. (2011). Una aproximación al turismo Slow: el turismo Slow en las Cittaslow de España. Investigaciones Turísticas, 1, 122-133.

Demaria, F. Kallis, G. i Bakker, K. (2019). Geographies of degrowth: Nowtopias, resurgences and the decolonization of imaginaries and places. Nature and Space, 2(3), 431-450.

Donaldson, R. (2017). Cittaslow: Going Nowhere Slowly? A R.Donaldson (ed.), Small Town Tourism in South Africa (87-117). New York: Springer International Publishing.

Espeitx, E. (2004). Patrimonio alimentario y turismo: una relación singular. Pasos, 2(2), 193-213.

Fletcher, R., Murray, I. M., Blanco-Romero, A., i Blázquez-Salom, M. (2019). Tourism and degrowth: an emerging agenda for research and praxis. Journal of Sustainable Tourism, 27(12), 17451763.

Frank, A. (2011). La conquista de lo cool. El negocio de la cultura y la contracultura y el nacimiento del consumismo moderno. Barcelona: Alpha Decay.

Gascón, J. (2018). Turismo, gastronomía y alimentación. De la teoría del enlace a la patrimonialización de la gastronomía. A F. X. Medina i M. del P. Leal (Eds.), Gastronomía y turismo en Iberoamérica (pp. 15-32). Gijón: Ediciones Trea.

Hakim, L., Siswanto, D., Rahardi, B. i Zayadi, H. (2019). Fostering coffee agroforestry for agrotourism development in degraded land in a buffer zone of a national park: A case study from Poncokusumo, Malang, Indonesia. EurAsian Journal of BioSciences, 13(2), 1613-1620.

Hernández, I., Jiménez-Ruiz, A., Castrejón, Y., Contreras, D. i Barquín R. (2020). Turismo agroalimentario y revalorización de alimentos tradicionales: el caso del Yatay en Ubajay, Argentina. Rosa dos Ventos - Turismo e Hospitalidade, 12(2), 309-333.

Hernández, R. i Dancausa, M.G. (2018). Turismo Gastronómico. La gastronomía tradicional de Córdoba (España). Estudios y perspectivas en turismo. 27, 413-430.

Ioannides, D. i Debbage, K. G. (1998). Neo-Fordism and Flexible Specialization in the Travel Industry. A D. Ioannides i K. Debbage (Eds.), The Economic Geography of the Tourist Industry: A Supplyside Analysis (pp. 97-119). Abingdon: Roudledge.

Latouche, S. (2006). Le Pari de la décroissance. Paris: Fayard.

Latouche, S. (2007). Petit traité de la décroissance sereine. Paris: Mille et Une Nuits.

Meng, B. i Choi, K. (2016). The role of authenticity in forming slow tourists' intentions: Developing an extended model of goal-directed behaviour. Tourism Management, 57, 397-410.

Medina, F. i Tresserras, J. (2008) Turismo enológico y rutes del vino en Cataluña. Análisis de casos: D.O. Penedès, D.O. Priorat y D.O.Montsant. PASOS, 6(3), 493-509.

Molleví, G. i Fusté, F. (2016). El turismo gastronómico, rutas turísticas y productos locales: el caso del vino y el queso en Cataluña. Geographicalia, 68, 25-47.

Mondéjar, J.A., Cordente, M., Mondéjar J. i Meseguer, M.L. (2009). Perfil del turista cultural: una aproximación a través de sus motivaciones. $\operatorname{Her} \& M u s, 2,25-58$.

Moscarelli, R. (2019). Slow tourism infrastructure to enhance the value of cultural heritage in inner areas. Il capitale culturale, 19, 237-254.

Oh, H., Assaf, G. i Baloglu, S. (2014). Motivations and Gloals of Slow Tourism. Journal of Travel Research, 55(2), 205-219.

Oliveira, S. (2011). La gastronomía como atractivo turístico primario de un destino. El turismo gastronómico en Mealhada - Portugal. Estudios y perspectivas en turismo. 20, 738-752.

Özdemir, G. i Çelebi, D. (2018). Exploring dimensions of slow tourism motivation, Anatolia, 29(4), 540-552.

Petrini, C. (2003). Slow Food: The Case for Taste. New York, United States: Columbia University Press.

Presenza, A., Abbate, T. i Alibrandi, A. (2014). From Conservation to Valorization of Heritage Assets: The Contribution of Cittaslow Certification. Heritage, Tourism and Hospitality: International Conference HTHIC 2014 November 6-8, 2014 Istanbul, Turkey / Boğaziçi University, Erasmus University, Adnan Menderes University and Elgin \& Co.

Ribas. J. i Mulet, M. (2018). Patrimonio alimentario, turismo y espectáculo. Reflexiones en torno a un proyecto de desarrollo de experiencias turísticas gastronómicas. A ODELA, Polisemias de la alimentación. Salud, desperdicio, hambre y patrimonio (pp. 77-96). Barcelona: Observatorio de la Alimentación - ODELA.

Rico, A., Martínez-Blanco, J., Montlleó, M., Rodríguez, G., Tavares, N., Arias, A., i Oliver-Solà, J. (2019). Carbon footprint of tourism in Barcelona. Tourism Management, 70, 491-504. 
Rullán, O. (2008). Reconversión y crecimiento de las zonas turística. Del fordismo al postfordismo. A M. A. Troitiño, J. S. García i M. García. Destinos turísticos: viejos problemas, ¿nuevas soluciones? (587-624). Cuenca: Ediciones de la Universidad de Castilla-La Mancha.

Serdane, Z., Maccarrone-Eaglen. A. i Sharifi, S. (2020). Conceptualising slow tourism: a perspective from Latvia. Tourism Recreation Research, preprint. Doi: https://doi.org/10.1080/02508281.2020.1726614.

Shang, W., Qiao, G. i Chen, N. (2019). Tourist experience of slow tourism: from authenticity to place attachment - a mixed-method study based on the case of slow city in China. Asia Pacific Journal of Tourism Research, 25(2), 170-188.

Timms, B. i Conway, D. (2012). Slow Tourism at the Caribbean's Geographical Margins. Tourism Geographies: An International Journal of Tourism Space, Place and Environment, 14(3), 396418.

Valls, J. F., Mota, L., Vieira, S. C. F., i Santos, R. (2019). Opportunities for slow tourism in Madeira. Sustainability, 11(17), 1-23.

Varley, P. i Semple, T. (2015). Nordic Slow Adventure: Explorations in Time and Nature. Scandinavian Journal of Hospitality and Tourism, 15(1-2), 73-90.

Wilson, S. i Hannam, K. (2017). The frictions of slow tourism mobilities: Conceptualising campervan travel. Annals of Tourism Research, 67, 25-36.

Woyesa, T. i Kumar, S. (2020). Potential of coffee tourism for rural development in Ethiopia: a sustainable livelihood approach. Environment, Development and Sustainability, preprint. Doi: https://doi.org/10.1007/s10668-020-00610-7.

Zúñiga, F. (2012) El patrimonio biocultural frente a los procesos de apropiación turística y mercantilización como estrategia de desarrollo para el Totonacapan veracruzano. A A. Castellanos i C. del Campo, C. (Coord.). Turismo y antropología: miradas del Sur y el Norte (233-266). México: Universidad Autónoma Metropolitana. 